\title{
The evolution of inter-regional spatial mismatch in the US: The role of skills and spatial structure
}

\author{
Tobias Theys, Nick Deschacht, Stef Adriaenssens and Dieter Verhaest ${ }^{1}$ \\ Forthcoming in Urban Studies
}

\begin{abstract}
The literature on spatial mismatch often focuses on a mismatch within cities or local labour markets. This paper looks at the spatial mismatch between local labour markets. Using US data, we study the evolution of inter-regional mismatch between 1980 and 2010 and how this evolution varies across skill levels. Since we expect the spatial structure of supply and demand in the labour market to play a central role at this geographical level, we develop an extension of the spatial mismatch index, as the standard version does not take this spatial structure into account. Our results indicate that spatial mismatch has been increasing over the past decades, an increase that is largely attributable to spatial structure effects. The inter-regional spatial mismatch mainly affects low-skilled jobs and workers: our findings suggest that the degree of the spatial mismatch for low-skilled, relative to high-skilled workers, increased from a ratio of two in 1980 to almost four in 2010 .
\end{abstract}

Citation: Theys, T., Deschacht, N., Adriaenssens, S. \& Verhaest, D. (2018). The evolution of inter-regional spatial mismatch in the US: The role of skills and spatial structure. Urban Studies, forthcoming.

\footnotetext{
${ }^{1}$ KU Leuven, Faculty of Economics and Business, ECON research group. Warmoesberg 26, 1000 Brussels, Belgium.

Corresponding author: Tobias Theys, tobias.theys@kuleuven.be
} 


\section{Introduction}

Ever since John Kain introduced the concept of spatial mismatch in his seminal article in 1968, in which he argued that a combination of housing segregation, discrimination, and the suburbanization of jobs led to Blacks facing strong geographic barriers in their search for suitable jobs, the importance of job accessibility has been a focal point in the literature that attempts to explain the difficulties of vulnerable population groups in the labour market. Over the years, a number of authors have tested the spatial mismatch hypothesis through different methodological approaches. The bulk of this literature confirms that access to jobs plays a substantial role in labour market outcomes (Gobillon et al. (2007), Holzer (1991), Ihlanfeldt and Sjoquist (1998), and Kain (1992), provide extensive literature reviews on the subject). While Kain's initial thesis (1968) concerned the specific case of Blacks in American city centres, research on spatial mismatch has since expanded to other contexts and population groups, generally, those groups that are more vulnerable, such as ethnic minorities, migrants and low-skilled workers. Decades later, spatial mismatch and job accessibility remain important topics. In a study that brings together different active streams and theoretical models, Gobillon et al. (2007) identified seven mechanisms that explain why distance to job opportunities can have a harmful impact on the chances of (minority) workers in the labour market. The common theme in these mechanisms is the presence of search and commuting costs that increase with distance, both for workers and firms.

Barring some exceptions, the literature mostly focuses on intra-regional spatial mismatch. In his recent book, The New Geography of Jobs (2012 pp 163-164), Enrico Moretti has reoriented the debate by arguing that the importance of spatial mismatch has not diminished, but that its main source is no longer found within but between cities. This adjustment from intra- to inter-regional mismatch can have repercussions for the policies used to address it. Ihlanfeldt and Sjoquist (1998) identify three types of policies: moving jobs to workers, moving workers to jobs, and making it easier for workers to reach the jobs. While the third 
type usually receives the bulk of the attention because of the potential for short-term cost-efficient results, this is only a valid policy to address (relatively) short-distance spatial mismatch (i.e., within local labour markets). Addressing a growing spatial mismatch between regions would require the use of one of the other two types of policies and would be more difficult to solve.

Although the calculation of spatial mismatch has made great strides, one important challenge that remains is the actual measurement of access to jobs (Gobillon et al., 2007) for which different streams of literature apply different methods. In the literature that focuses on local job accessibility, researchers estimate extensive models that take into account access to jobs by using decay functions or gravity models based on physical distance or commuting time, weighing nearby jobs more heavily (Bunel and Tovar, 2014; DétangDessendre and Gaigné, 2009; Korsu and Wenglenski, 2010).

One of the more straightforward methods to measure spatial mismatch used in literature is the spatial mismatch index (SMI) (Easley, 2018; Liu and Painter, 2012; Stoll and Covington, 2012), initially put forward by Martin (2001). The SMI is an adaptation of the dissimilarity index, originally developed to analyse racial segregation (Duncan and Duncan, 1955). Essentially, it compares the distribution of jobs and the population over a number of areal units (such as counties within a metropolitan area), implicitly assuming that the population in an areal unit only has access to jobs in that unit. The more uneven these distributions, the higher the value of the spatial mismatch index is. While the SMI is easy to calculate and interpret, making it an attractive method for analysing large data sets (e.g. different population groups or points in time), it has a weakness in that it is essentially a-spatial. It ignores the spatial structure of the areal units since the degree of spatial mismatch is considered separately in every areal unit, and any possibility of interaction between the units is not taken into account (Liu and Painter, 2012; Stoll, 2006).

If we want to analyse the evolution of inter-regional mismatch, the lack of accounting for distance in the SMI is problematic. Other papers in the literature strengthen this notion of the persistence of local 
employment patterns (Amior and Manning, 2018; Overman and Puga, 2002; Patacchini and Zenou, 2007). If local labour markets share specific characteristics due to their proximity to each other, distance can play a key role in the size and impact of the mismatch. The regular spatial mismatch index could therefore be significantly biased compared to the true size of the spatial mismatch.

This paper proposes an extension of the spatial mismatch index, taking into account the spatial structure of the population and employment distributions to analyse the evolution of inter-regional spatial mismatch between 1980 and 2010 in the US. Using data on jobs and population for metropolitan statistical areas, we investigate whether the evolution of the degree of spatial mismatch is in line with Moretti's (2012) claim of an increasing mismatch between regions. Since this "great divergence" would disproportionally affect low-skilled workers, we calculate values for the population as a whole and the high- and low-skilled population separately. We then decompose the change in spatial mismatch into a part attributable to changes in employment distribution and a part attributable to changes in the population distribution.

The remainder of this paper is organized as follows. Section 2 discusses the notion of an increased interregional mismatch. The third section discusses the shortcoming of the SMI and develops the extension, and the fourth section describes the data used. Section 5 presents the results, and section 6 discusses the findings and concludes.

\section{The rise of inter-regional mismatch}

The evidence presented by Moretti (2012) suggests that economically thriving regions in the US are becoming more and more geographically disconnected from regions with poor labour market conditions a trend he refers to as 'the great divergence'. Regions with industries that have innovation at their centre have flourished, attracting high-skilled workers and offering high wages, while prosperity in regions with declining industries, such as manufacturing, has declined, with high-skilled workers leaving and low wages 
for the workers that stay behind. In this divergence, elements of both the supply and demand side of the labour market play a role.

On the demand side, the concentration of specific industries in certain regions (e.g. technology in Silicon Valley) has strongly linked the fate of these regions to that of the industries. This link between industry specialisation and economic performance of a region has been discussed extensively in the literature. While traditional location theory is heavily focused on cost-efficiency, with firms settling near key suppliers or customers in regions with proper infrastructure to limit the cost of transportation, the identification of alternative mechanisms dates back to Marshall (1890), who was one of the first to elaborate on the existence of externalities, such as knowledge spillovers between firms. Arrow (1962) and Romer (1986) expanded on this theory and stressed the importance of similar activities and geographical proximity to make these spillovers between firms possible. These intra-industry (or inter-industry between similar industries) spillovers lead to firms settling in regions with a strong presence of comparable firms (Glaeser et al., 1992) and thus a strong concentration and specialization of the region. Knowledge spillover is not the only mechanism that can lead to the localization of industries. Krugman (1991) mentions three reasons that exist in the literature: apart from the knowledge spill-overs, a localized industry allows the creation of a specialized labour market pool, ensuring a lower probability of labour shortages, and makes the production of non-tradable specialized inputs possible.

For these mechanisms to reward the concentration of firms, there needs to be a certain degree of tacit knowledge present in the industry. For more traditional production, cost factors might still be the most critical factor in deciding on a location (Christensen and Drejer, 2005), a theory supported by the frequent relocation of these industries to countries with lower wages. Conversely, knowledge-intensive or innovation-oriented industries, such as the high-tech industry, seem to experience sizeable rewards through concentration (Kelly and Hageman, 1999; van der Panne, 2004). Although the existence of concentration 
effects is generally acknowledged in the literature, there is a debate upon which geographical and industry level they act (Beaudry and Schiffauerova, 2009).

The regions that can attract these concentrated industries profit not only through the additional economic performance within these industries but also through an increase in demand for local services, creating a multiplier effect. This dynamic is especially strong for industries that attract high-skilled workers, who usually earn higher wages: driven by their high opportunity cost of time, their demand for time-intensive services, often carried out by low-skilled workers, will increase (Mazzolari and Ragusa, 2013). Moretti (2010) estimates an additional unskilled job in manufacturing in a city creates one new job in the locationbound sectors in that city. For an additional high-skilled job, this multiplier increases to 2.5 .

The other side of the coin concerns regions that were once highly popular due to cost- and transportationrelated factors such as good infrastructure, reachability, and a large local market. As costs of transportation and communication have gone down and wages have risen, these regions have lost their strategic advantage regarding cost-minimizing industries, which acted as an essential driver of prosperity in the past. The literature corroborates this theory on the US labour market effects of import competition with China, which shows the importance of location resulting from initial regional patterns of industry specialization (Autor et al., 2016).

On the supply side of the labour market, there is an important role for labour mobility: the willingness to move away from declining towards prosperous regions could balance out the shift on the demand side, thereby countering the increasing mismatch. However, Molloy et al. (2011) find that while US citizens show a higher propensity to move compared to other developed countries, this mobility has declined overall in the 2000s compared to the $1980 \mathrm{~s}$, breaking from a pattern of increasing mobility since the $1900 \mathrm{~s}$ (Rosenbloom and Sundstrom, 2004). Furthermore, mobility depends on the education level, with the lowskilled workers being rather immobile (Green and Owen, 2006; Malamud and Wozniak, 2012). In a recent 
paper, Amior (2017) finds that the low returns that moving would yield can explain the immobility of lowskilled workers, both for the firm and worker. These low returns also encourage both sides to focus their search on a more local scale. The situation is different for the high-skilled, where the high expected surplus of a match encourages firms and workers to search in a wider area for the right match.

Research on the persistence of local unemployment patterns brings together these two sides of the labour market. One key factor in the existence of local unemployment patterns is the degree of commuting, which links the faith of nearby regions (Patacchini and Zenou, 2007). Amior and Manning (2018) find that while there is a strong migratory response to demand shocks, it is insufficient, with adjustment to a shock remaining incomplete a decade later. Furthermore, these demand shocks are often persistent and serially correlated. Using European data, Overman and Puga (2002) found that polarization between regions is demand-driven and that changes on the supply-side of the labour market have a de-polarizing effect, with population growth predominantly found in regions with a low unemployment level.

\section{Methodology}

To analyse the evolution of spatial mismatch over time between regions, we develop an extension of the spatial mismatch index (SMI), which compares the distribution of jobs and workers over an area that is divided into $n$ areal units. If $j_{i}$ is the number of jobs in areal unit $i, p_{i}$ the size of the population in $i$ and $j$ and $p$ the total number of jobs and size of the population in the whole area, the SMI compares the share of the population to the share of jobs in every areal unit and aggregates these results:

$$
S M I=\frac{1}{2} \sum_{i=1}^{n}\left|\frac{p_{i}}{p}-\frac{j_{i}}{j}\right|
$$

The index lies between 0 (perfectly equal distribution of population and jobs) and 1 (perfectly unequal distribution of population and jobs). The value can be interpreted as the share of the population (or jobs) that would have to move from areal units with a relative population surplus to units with a relative shortage 
to achieve an equal distribution. The intuitive and direct interpretation of the SMI makes it a convenient method to analyse and compare degrees of spatial mismatch at different points in time (Liu and Painter, 2012) and between population groups (Easley, 2018). However, it has a notable weakness that could have a significant impact in the context of analysing spatial mismatch between regions: the SMI ignores the spatial structure of the areal units (Liu and Painter, 2012; Stoll, 2006), an issue that had already been raised for the dissimilarity index (Jakubs, 1981; Wong, 1993). Consider a person living in a specific areal unit with a relative population surplus. If an adjacent unit has a relative population shortage, this person would not have to move far to reduce the spatial mismatch measured through the SMI. However, if the adjacent units have a relative surplus as well, the movers would have to cover a larger distance to reach units with relative shortages. The SMI does not differentiate between these scenarios; it does not consider the distance between the population and jobs.

One way to deal with this shortcoming would be to complement the result of the SMI by an indicator of spatial association, such as Moran's I (Moran, 1950), which measures the global spatial autocorrelation in an area. If more refinement is warranted, local indicators of spatial association (Anselin, 1995) can be used to decompose a global indicator such as Moran's I. A second way to deal with this weakness is to look for alternative indices that do a better job of including the influence of location. Unfortunately, the alternative indices suggested in literature (Feitosa et al., 2007; Reardon and O’Sullivan, 2004; Wong, 1993) often give up in ease of interpretation what they gain in the sophistication of measurement. In this paper, we construct an index that takes the spatial structure into account but keeps the convenient interpretation intact. We follow Jakubs' (1981) idea to include the distance between areal units when measuring the effort required to arrive at an even distribution over the whole area. Where the dissimilarity index measures segregation through the number of people that have to move, Jakubs (1981) estimates the total distance that these people have to move. This idea translates easily to the context of spatial mismatch, in which we can calculate the 
total minimum distance that a part of the population has to travel from areal units with a relative population surplus to units with a relative shortage to remove the mismatch.

Contrary to Jakubs (1981), we express the relative surpluses and shortages in shares rather than absolute numbers and standardise the measurement of distance to directly arrive at an interpretable index, instead of obtaining a result that depends on the total size of the population and the size of the area under consideration. To standardise distance, we set the distance between the two areal units that are furthest from each other equal to one, which turns distance into a weighting measure, where movements over greater distances are weighted more heavily. Although the scaling helps us to arrive at an interpretable index, the upper limit of the created index is directly linked to the region under consideration, since it depends on the maximum distance in the sample. Given our empirical framework only considers a fixed region through time, this characteristic is not problematic, but it would have an impact in contexts where comparisons are made between different regions. The distance-weighted spatial mismatch index (DSMI) is constructed in three steps. In the first one, we calculate $s_{i}$, the difference between the share of the population and jobs, for every areal unit, identical to the first step of the calculation of the SMI, since $s_{i}=\frac{p_{i}}{p}-\frac{j_{i}}{j}$. A positive $s_{i}$ indicates a relative population surplus.

In the second step, every $s_{i}$ is weighted by the effort it would take to eliminate the mismatch, measured by the distance $d$ that movers would have to travel from areal units with a relative surplus (origins) to units with a relative population shortage (destinations). We assume the group that needs to move does so in a rational manner by minimizing the total moving distance $\sum_{i, j} s_{i j} d_{i j}$, where $\mathrm{s}_{i j}$ is the share of movers from origin-unit $i$ to destination-unit $j$, and $d_{i j}$ is the standardised distance between these areal units. Calculating the DSMI then turns into a minimization problem:

$D S M I=\min _{s_{i j}} \sum_{i, j} s_{i j} d_{i j}$ 


$$
\text { subject to: } \sum_{j} s_{i j}=s_{i} \forall i ; \quad \sum_{i} s_{i j}=-s_{j} \forall j ; \quad s_{i j} \geq 0 \forall i, j .
$$

The result of this minimization, which lies between zero and one, will generally be lower than the SMI, since the upper bound of the DSMI (DSMI=1) represents the very extreme scenario in which the population and jobs are located as far away from each other as possible.

Due to the way the DSMI is defined, the relationship between the SMI and the DSMI is straightforward: $\mathrm{DSMI}=\mathrm{SMI} \times \mathrm{D}$, where $\mathrm{D}$ is the average (standardized) distance that those who have to move, need to travel. Each of the three parts can be transformed into a more tangible number: multiplying the SMI by the total size of the population (or jobs) gives us the number of people (or jobs) that would have to move to eliminate the mismatch, multiplying $\mathrm{D}$ by the distance between the two areal units that are furthest away from each other (used in the standardization process) yields the average distance that these people need to travel, and multiplying the DSMI by both the size of the population and the maximum distance leads to the total minimum distance that needs to be travelled to eliminate the spatial mismatch.

By comparing the DSMIs of two consecutive decades, we can infer whether there has been a convergence in the distribution of population and jobs, but not whether this convergence can be attributed to the relocation of jobs or population (or both). To separate these effects, we follow Martin (2004) and Liu and Painter (2012) and calculate a mixed DSMI, by holding the population distribution constant and only taking changes in the job distribution into account as a measure for the impact of employment shifts. Subsequently, the difference between the full change in the DSMI and the change due to employment shifts can be attributed to population shifts. The choice to keep the population distribution constant while letting the employment distribution vary is not arbitrary and is based on the assumption that decisions to relocate happen on a shorter timeframe for the population, while relocation processes for companies and the accompanying employment take more time. 


\section{Data}

The primary analyses in this study are carried out at the level of US metropolitan statistical areas (MSAs), while data are drawn from several sources at the county level. The main reason for this choice is consistency through time: the definitions and delineations of MSAs have gone through significant changes in the time period we consider (1980-2010), but this is much less the case for counties. We, therefore, use the definition and delineation of the MSAs of 2015 and link counties to these MSAs using data from the Bureau of Economic Analysis. Given their location away from the US mainland, we exclude Alaska and Hawaii.

Data on employment are drawn from the County Business Patterns database. For some counties, exact employment data are withheld for disclosure reasons, and only an interval is given, in which case we use the middle value of the interval. County Business Patterns only provides employment data by industry and not by skill. To estimate the skill-specific number of jobs in each county, we draw census data through Integrated Public Use Microdata Series (IPUMS) for each decade to estimate the fraction of employment in each industry (on a two-digit SIC/NAICS level) that is low-skilled (less than a high school degree) and high-skilled (at least four years of college). These fractions are then used to estimate the number of jobs for low-skilled and high-skilled workers in each county. Given our focus on the comparison of the trajectory of the low-skilled with that of the high-skilled, we will not separately consider the middle-skilled group. Data on population and educational attainment come from two sources: for the first three decades (19802000), census data prepared by the USDA Economic Research Service is used. Because this county-level data is incomplete for 2010, we use the 5-year average (2010-2014) from the Community Survey data. All data refer to the population of 25 years of age and older in each county.

Location data for each MSA are drawn from the US Census Bureau and distances are calculated between the centroids of these areas using the Stata module "vincenty" (Nichols, 2003), which calculates the greatcircle distance between two points. While the distance between the centroids is a reasonably simple way to 
estimate the effort it takes to move between MSAs and eliminate spatial mismatch, a more advanced method to measure this effort would lead to results that are less easy to interpret, thereby taking away one of the important strengths of our spatial mismatch index. The optimizations required for estimating equation (2) are performed using mixed integer linear programming using the CPLEX solver.

Panel A of table 1 shows a number of descriptive statistics for the sample as a whole. Both the total size of the population and the total number of jobs increase from period to period, except for the total number of jobs between 2000 and 2010. Presumably, this drop is caused by the impact of the financial crisis. With regards to the share of low- and high-skilled workers in the total population, we see the percentage of lowskilled in the population decreases sharply through time, while the share of high-skilled evolves in the opposite direction. A similar evolution takes place with regard to low- and high-skilled jobs. The share of low-skilled workers is consistently higher than the share of low-skilled jobs, whereas this gap is consistently smaller between high-skilled workers and high-skilled jobs, although the latter gap shrinks through time.

Panel B shows descriptive statistics regarding the 378 metropolitan areas in the sample. The metropolitan area with the largest population in 1980, New York-Newark-Jersey City, contains $9.5 \%$ of the total population. Even though it still had the highest population share in 2010 , it is only $7.7 \%$ of the total population. New York-Newark-Jersey City also has the highest share of jobs in 1980 and 2010, and the shares and evolution are remarkably similar to that of the population, decreasing from $9.7 \%$ to $7.7 \%$. Riverside-San Bernardino-Ontario in California has the largest positive difference between population and jobs, both in 1980 (0.3 pp) and 2010 (0.5 pp), while respectively Los Angeles-Long Beach-Anaheim (-1.0 pp) and Boston-Cambridge-Newton (-0.5 pp) have the largest negative difference in 1980 and 2010. As for the evolution between 2010 and 1980, New York-Newark-Jersey City experienced both the greatest drop in the share of the population $(-2.0 \mathrm{pp})$ and share of jobs $(-1.7 \mathrm{pp})$. The largest negative change in the difference between population share and employment share is Washington-Arlington-Alexandria (-0.4 pp). As for the positive changes, Dallas-Fort Worth-Arlington experienced the largest increase in population 
share (0.8 pp), while Washington-Arlington-Alexandria experienced the largest increase in job share (0.7 pp). The largest positive change in the difference between population and job share is Los Angeles-Long Beach-Anaheim, increasing by $0.9 \mathrm{pp}$.

\section{Results}

Table 2 reports the values of the DSMI for the low-skilled, high-skilled, and total population for each decade. Comparing the overall values of the DSMIs of the different population groups, we see the DSMI for the low-skilled population is consistently higher than that of the high-skilled and total population in every time period. Looking at the changes through time, we see that the total population and the high-skilled population have experienced opposite results. Where the DSMI increased progressively in each period for the population as a whole, ultimately increasing by 0.7 percentage points ( $\mathrm{pp}$ ) over the three decades under consideration, it decreased in each period for the high-skilled group, equalling a total decrease of $0.5 \mathrm{pp}$. The evolution for the low-skilled is quite peculiar: while they experienced a decrease of $1.3 \mathrm{pp}$ in the DSMI in the first period, this decrease is entirely negated by the subsequent increases in the second and third periods, leading to an increase in the DSMI of $1.1 \mathrm{pp}$ over the period as a whole.

Over the course of three decades, the spatial mismatch has increased for the population as a whole and the low-skilled, while it has decreased for the high-skilled. The spatial mismatch has increased from twice as high for the low-skilled compared to the high-skilled in 1980, to almost four times as high in 2010.

In the framework proposed by Moretti (2012), we would assume shocks in the distribution of employment have played an essential part in this evolution, with low- and high-skilled jobs moving away from areas with a high number of low-skilled workers and towards areas with a high number of high-skilled workers. Furthermore, given the higher mobility of the high-skilled, we could also expect this group to follow the movement of suitable jobs, while this would be less so for low-skilled workers. To check the validity of 
these expectations, we follow Liu and Painter (2012) and Martin (2004) and decompose the change of the DSMI into two parts: one part that is attributable to changes in employment distribution and a second part attributable to changes in population distribution, where the sum of the two is equal to the change in the DSMI between the two periods. The employment shift is measured by using population data of one period and job data of the next, the population shift by calculating the difference between the change in the DSMI and the employment shift. The results of these decompositions are shown in table 3 , with a separate panel for each population group.

Looking at the results, we see that over the period as a whole for the total and low-skilled population, the shift in employment distribution would have led to a severe divergence between the distributions if the population distribution would have remained equal to that in $1980(+2.3 \mathrm{pp}$ and $+3.0 \mathrm{pp})$. However, the simultaneous shift in population distribution managed to partly counteract this effect, even though the resulting change in the spatial mismatch is still positive. Looking at the decades separately, we see that the results are more nuanced, indicating that changes in employment and population distribution have partly coincided within these periods, although these results still show a strong diverging effect from the employment shifts. For the high-skilled population, the effect of the employment shifts is positive but close to zero, indicating that jobs between 1980 and 2010 moved away from the high-skilled population in 1980. However, this divergence is rather small and more than compensated by the change in the population distribution over these thirty years, leading to an overall convergence between the two distributions as measured by the DSMI. The results for the separate decades again show a more nuanced evolution.

The way we constructed the DSMI allows us to break it up into two parts, one of which is the original SMI and the other the average distance $\mathrm{D}$, the de-standardized average of the distance $d_{i j}$ we defined as a measure of the effort it would take per mover to eliminate the spatial mismatch, capturing the location-driven mismatch. For ease of interpretation, we will discuss the de-standardized version of D by multiplying it 
with the distance we used in the standardization process (2778.4 miles). The values of the DSMI, SMI and D for each decade can be found in table 4.

A comparison of the SMI and the DSMI shows several instances where there is a substantial difference between the values and evolution of the two indices, such as the change from 1980 to 1990 for the lowskilled population, which is much more pronounced when measured by the DSMI. More importantly, the SMI reports a decrease of spatial mismatch over the whole period from $6.5 \%$ to $5.7 \%$, a decrease of $0.8 \mathrm{pp}$. However, according to the DSMI, spatial mismatch practically doubled. Not taking into account the location-driven mismatch would lead to a significant underestimation of certain evolutions of spatial mismatch.

Analysing D and its evolution yield some interesting results: for the high-skilled population, the distance remains relatively stable, starting from 588.5 miles on average in 1980, decreasing slightly in every time period, to end up at 535.4 miles in 2010. This is not the case for the low-skilled group, as was to be expected from the discrepancies between the SMI and DSMI: the average distance that needs to be travelled decreases from 803.8 miles to 516.7 miles between 1980 and 1990, stays relatively stable in the next period to increase by $52.7 \%$ between 2000 and 2010 , ending up at an average of 851.5 miles that needs to be travelled per mover. Where the high-skilled workers end up having to move approximately 53 miles less in 2010 compared to 1980 , it is approximately 48 miles more for the low-skilled; while in 1980 a low-skilled mover had to travel an average distance of 1.4 times the average distance of a high-skilled mover, in 2010 this difference has grown to 1.6. For the population as a whole, the average distance to be travelled has increased progressively over the time periods, ending up with an average distance in 2010 that is double the distance of 1980 .

Given the central role of distance in our calculations, the choice of which distance measure to use is essential. The choice for the basic linear distance between the areas is mostly pragmatic, since it allows us 
to keep the advantage inherent to the spatial mismatch index, the straightforwardness of use and interpretation, intact. By multiplying the value of the DSMI by the total population and the maximum distance between the two areas furthest away from each other, the result can be interpreted as the total distance that needs to be moved to eliminate the mismatch. Furthermore, by using linear distance, the decomposition of the DSMI leads to the original SMI on the one hand and a tangible, interpretable value for the importance of distance in the mismatch on the other hand.

To analyse the robustness of our results with regards to the measure of distance used, we repeat the calculations of the DSMIs using three alternatives, all standardised to arrive at an index between zero and one directly. The first alternative we use is the natural logarithm of the linear distance. This alternative could be relevant in a context where an increase in distance that needs to be moved becomes less critical when the distance is already significant. The second and third alternative are both based on the idea of concentric circles: both alternatives use four circles, where destinations in the smallest circle are assigned a distance equal to one, the destinations in the second circle a distance equal to two, etcetera. The radii differ between the two alternatives: in the second alternative, we use the distance blocks used by the US Census Bureau in their reporting on inter-county migration: under 50 miles, between 50 and 250 miles, between 250 and 500 miles, and more than 500 miles. The radii of the third alternative are based on the distance-percentiles in the linear distance-matrix: destinations with a distance under the $25^{\text {th }}$ percentile get a value of one, destinations with a distance between the $25^{\text {th }}$ and the $50^{\text {th }}$ percentile a value of two, destinations between the $50^{\text {th }}$ and the $75^{\text {th }}$ percentile a value of three, and distances larger than the $75^{\text {th }}$ percentile a value of four. Table 5 presents the comparisons of the DMSI using the original distance measure, the regular SMI (excluding any measure of distance), and the three distance-based alternatives.

The values of alternative one and two lie close together, which is to be expected given that the first alternative has a low penalty for extra distance when the distance is already significant, and the second alternative treats every distance greater than 500 miles equally. All in all, the values of the three alternatives 
and the change in spatial mismatch they measure are similar to that of the DSMI, although only the third alternative picks up on the increase in the spatial mismatch for the population as a whole like the DSMI does. As we saw in the previous section, the average distance that needs to be moved doubled between 1980 and 2010 for the population as a whole, from 358 to 726 miles per mover. Since the first and second alternative put a lower emphasis on large distances, they do not adequately take into account this marked increase.

\section{Discussion}

We explored two theses posited by Moretti (2012): first, the level of spatial mismatch has increased between regions in the US over the last decades and second, this increase has mainly impacted the low-skilled population. Since we expected the spatial structure of labour supply and demand to play a key role, we developed a distance-weighted spatial mismatch index (DSMI) to test these hypotheses as the standard spatial mismatch index (SMI) does not take this spatial structure into account.

With regards to the first of these, the results differ between the SMI and the DSMI. While the SMI reports a small decrease of spatial mismatch, the DSMI shows a marked increase. This discrepancy exemplifies the importance of including a measure of distance in the analysis and strengthens the idea that location-driven factors play a crucial role. While the alternative measures for distance mostly confirm our results, they do show that how we choose to deal with changes in distance impacts the results: if we assume that the cost of an extra mile decreases as distance increases, the resulting DSMI is closer to the value of the SMI. The decomposition of the change in spatial mismatch into employment and population shocks show that without a simultaneous change in population distribution, the shift in employment would have resulted in a much larger divergence between the two distributions, indicating that jobs did not move towards the location of the 1980 population. The decomposition per decennium is more nuanced, showing that the changes in employment and population happened more gradually. 
The results for the high- and low-skilled population demonstrate that the evolution on an aggregated level hide critical skill-specific variations in the trend: while the high-skilled experienced a decrease in the spatial mismatch between 1980 and 2010, it has increased for low-skilled workers. In 2010, the low-skilled face a spatial mismatch almost four times as high compared to the mismatch for the high-skilled, while it was only twice as high in 1980. Looking at the decomposition of the DSMI into the SMI and distance for both groups, we see both factors have contributed to the increase in the gap between them. Not including distance would misrepresent the divergence between these groups, as it would underestimate both the decrease in the spatial mismatch for the high-skilled and the increase for the low-skilled. The alternative measures of distance confirm the robustness of our results: all measures yield similar conclusions, with an increasing mismatch for the low-skilled and a decreasing one for the high-skilled.

The decomposition into employment and population shocks shows changes between 1980 and 2010 in the employment distribution have been strongly divergent from the location of the low-skilled in 1980, but simultaneous shifts in population managed to counteract this divergence to a certain degree. The shifts per decade are also strong between 1980 and 1990 and between 1990 and 2000, implying that at the beginning of these periods, low-skilled jobs were consistently moving away from the location of the low-skilled population. For the high-skilled, the impact of the shift in employment distribution between 1980 and 2010 is divergent but small, while the simultaneous shift in the population distribution led to a convergence between the employment and population distribution. In a per-decade timeframe, employment moved closer towards the population distribution at the start of the time period between 1980 and 1990 and between 2000 and 2010. These results are not surprising since we expected an interaction between high-skilled jobs moving towards high-skilled workers and high-skilled workers moving towards suitable jobs, given their greater mobility due to the greater potential return (Amior, 2017). 
Overall, we can conclude that our results confirm both theses: inter-regional spatial mismatch has increased between 1980 and 2010 for the population as a whole and has disproportionately affected the low-skilled, while the high-skilled experienced a simultaneous decrease in their degree of spatial mismatch.

\section{Funding}

Project subsidized by the Brussels-Capital Region - Innoviris.

\section{Acknowledgements}

We thank three anonymous reviewers and the participants of the 2017 SDLM workshop (Mannheim) for their valuable comments and suggestions.

\section{References}

Amior M (2017) Education and Geographical Mobility: The Role of Wage Rents. Available at: http://sites.google.com/site/michaelamior (accessed 19 May 2018).

Amior M and Manning A (2017) The persistence of local joblessness. American Economic Review, forthcoming.

Arrow K (1962) Economic welfare and the allocation of resources for invention. In: Nelson R (ed) The Rate and Direction of Inventive Activity. Princeton: Princeton University Press, pp. 609-626.

Autor DH, Dorn D and Hanson GH (2016) The China shock: Learning from labor market adjustment to large changes in trade. Annual Review of Economics 8: 205-240.

Beaudry C and Schiffauerova A (2009) Who's right, Marshall or Jacobs? The localization versus urbanization debate. Research Policy 38(2): 318-337. 
Bunel M and Tovar E (2014) Key Issues in Local Job Accessibility Measurement: Different Models Mean Different Results. Urban Studies 51: 1322-1338.

Christensen J and Drejer I (2005) The strategic importance of location: Location decisions and the effects of firm location on innovation and knowledge acquisition. European Planning Studies 13(6): 807-814.

Détang-Dessandre C and Gaigné C (2009) Unemployment duration, city size, and the tightness of the labor market. Regional Science and Urban Economics 39(3): 266-276.

Duncan OD and Duncan B (1955) A methodological analysis of segregation indices. American Sociological Review 20(2): 210-217.

Easley J (2018) Spatial mismatch beyond black and white: Levels and determinants of job access among Asian and Hispanic subpopulations. Urban Studies 55(8): 1800-1820.

Feitosa FF, Câmara G, Monteiro AMV et al. (2007) Global and local spatial indices of urban segregation. International Journal of Geographical Information Science 21(3): 299-323.

Glaeser EL, Kallal HD, Scheinkman JA et al. (1992) Growth in Cities. Journal of Political Economy 100(6): 1126-1152.

Gobillon L, Selod H and Zenou Y (2007) The mechanisms of spatial mismatch. Urban Studies 44(12): 2401-2427.

Green AE and Owen D (2006) The geography of poor skills and access to work. York: Joseph Rowntree Foundation.

Holzer HJ (1991) The spatial mismatch hypothesis: what has the evidence shown? Urban Studies 28(1): 105-122. 
Ihlanfeldt KR and Sjoquist DL (1998) The spatial mismatch hypothesis: A review of recent studies and their implications for welfare reform. Housing Policy Debate 9(4): 849-892.

Jakubs JF (1981) A distance-based segregation index. Socio-economic Planning Sciences 15(3): 129-136.

Kain JF (1968) Housing segregation, Negro employment and metropolitan decentralization. The Quarterly Journal of Economics 82(2): 175-197.

Kain JF (1992) The spatial mismatch hypothesis: Three decades later. Housing Policy Debate 3(2): 371460.

Kelly M and Hageman A (1999) Marshallian externalities in innovation. Journal of Economic Growth 4(1): $39-54$.

Korsu E and Wenglenski S (2010) Job accessibility, residential segregation, and risk of long-term unemployment in the Paris region. Urban Studies 47(11): 2279-2324.

Krugman P (1991) Increasing returns and economic geography. Journal of Political Economy 99(3): 483499.

Liu CY and Painter G (2012) Immigrant settlement and employment suburbanisation in the US: Is there a spatial mismatch? Urban Studies 49(5): 979-1002.

Malamud O and Wozniak A (2012) The impact of college on migration: Evidence from the Vietnam generation. Journal of Human Resources 47(4): 913-950.

Marshall A (1890) Principles of Economics. London: Macmillan.

Martin RW (2001) The adjustment of black residents to metropolitan employment shifts: how persistent is spatial mismatch? Journal of Urban Economics 50(1): 52-76. 
Martin RW (2004) Can black workers escape spatial mismatch? Employment shifts, population shifts, and black unemployment in American cities. Journal of Urban Economics 55(1): 179-194.

Mazzolari F and Ragusa G (2013) Spillovers from high-skill consumption to low-skill labor markets. Review of Economics and Statistics 95(1): 74-86.

Molloy R, Smith CL and Wozniak A (2011) Internal migration in the United States. Journal of Economic Perspectives 25(3): 173-196.

Moretti E (2010) Local multipliers. American Economic Review 100(2): 373-377.

Moretti E (2012) The New Geography of Jobs. New York: Houghton Mifflin Harcourt.

Nichols A (2003) Vincenty: Stata module to calculate distances on the Earth's surface. Statistical Software Components S456815, Boston College Department of Economics, revised 16 Feb 2007.

Overman H and Puga D (2002) Unemployment clusters across Europe's regions and countries. Economic Policy 17(34): 115-147.

Patacchini E and Zenou Y (2007) Spatial dependence in local unemployment rates. Journal of Economic Geography 7(2): 169-191.

Reardon SF and O'Sullivan D (2004) Measures of spatial segregation. Sociological Methodology 34(1): 121-162.

Romer PM (1986) Increasing returns and long-run growth. Journal of Political Economy 94(5): 1002-1037.

Rosenbloom JL and Sundstrom WA (2004) The decline and rise of interstate migration in the United States: Evidence from the IPUMS, 1850-1990. In: Field A (ed) Research in Economic History, Volume 22. Amsterdam and San Diego: Elsevier, pp.289-325. 
Ruggles S, Genadek K, Goeken R et al. (2017) Integrated Public Use Microdata Series: Version 7.0 [dataset]. Minneapolis: University of Minnesota. https://doi.org/10.18128/D010.V7.0.

Stoll MA (2006) Job sprawl, spatial mismatch, and black employment disadvantage. Journal of Policy Analysis and Management 25(4): 827-854.

Stoll MA and Covington K (2012) Explaining racial/ethnic gaps in spatial mismatch in the US: The primacy of racial segregation. Urban Studies 49(11): 2501-2521.

van der Panne G (2004) Agglomeration externalities: Marshall versus Jacobs. Journal of Evolutionary Economics 14(5): 593-604.

Wong DWS (1993) Spatial indices of segregation. Urban Studies 30(3): 559-572. 
Table 1. Descriptive statistics.

Panel A. General descriptive statistics for the full sample.

\begin{tabular}{ccccc}
\hline & 1980 & 1990 & 2000 & 2010 \\
\hline Total jobs & $64,650,524$ & $81,835,000$ & $99,744,952$ & $96,476,464$ \\
Low-skilled jobs (\%) & 23.9 & 12.4 & 9.7 & 8.6 \\
High-skilled jobs (\%) & 19.8 & 25.1 & 27.3 & 32.2 \\
Total population & $108,433,648$ & 131775,088 & 151997,136 & 176543,888 \\
Low-skilled population (\%) & 31.8 & 23.5 & 18.9 & 13.3 \\
High-skilled population $(\%)$ & 17.5 & 21.9 & 26.2 & 31.2 \\
\hline
\end{tabular}

Panel B. Descriptive statistics on the metropolitan statistical area level.

\begin{tabular}{ccccc}
\hline & $\mathrm{N}=378$ & Minimum & Maximum & Standard deviation \\
\hline \multirow{2}{*}{$1980(\%)$} & Job share & 0.0 & 9.5 & 0.7 \\
& Population share & 0.0 & 9.7 & 0.7 \\
& Difference & -1.0 & 0.3 & 0.1 \\
\hline \multirow{2}{*}{$2010(\%)$} & Job share & 0.0 & 7.7 & 0.6 \\
& Population share & 0.0 & 7.7 & 0.6 \\
Change between 1980 & Difference & -0.5 & 0.5 & 0.1 \\
and 2010 $(\mathrm{pp})$ & Job share & -1.7 & 0.7 & 0.2 \\
& Population share & -2.0 & 0.8 & 0.2 \\
\hline \hline
\end{tabular}

Source: County Business Patterns, decennial censuses and Community Survey. Descriptive statistics for the middle-skilled population are not presented.

Table 2. Values of the distance-weighted spatial mismatch index for the total, low-skilled and high-skilled population, 1980-2010.

\begin{tabular}{cccccc}
\hline & $\begin{array}{c}\mathbf{1 9 8 0} \\
(\boldsymbol{\%})\end{array}$ & $\begin{array}{c}\mathbf{1 9 9 0} \\
(\boldsymbol{\%})\end{array}$ & $\begin{array}{c}\mathbf{2 0 0 0} \\
(\boldsymbol{\%})\end{array}$ & $\begin{array}{c}\mathbf{2 0 1 0} \\
(\boldsymbol{\%})\end{array}$ & $\begin{array}{c}\text { Change between } \\
\mathbf{1 9 8 0} \text { and 2010 (pp) }\end{array}$ \\
\hline Total & 0.8 & 0.9 & 1.1 & 1.5 & 0.7 \\
Low-skilled & 3.4 & 2.1 & 2.8 & 4.5 & 1.1 \\
High-skilled & 1.7 & 1.5 & 1.4 & 1.2 & -0.5 \\
\hline \hline
\end{tabular}

Source: County Business Patterns, decennial censuses and Community Survey. 
Table 3. Decomposition of the change in the distance-weighted spatial mismatch index, 1980-2010.

Panel A. Change in the spatial mismatch for the total population.

\begin{tabular}{cccc}
\hline & $\begin{array}{c}\text { Total change in the spatial } \\
\text { mismatch }(\mathbf{p p})\end{array}$ & Employment shifts (pp) & Population shifts (pp) \\
\hline $\mathbf{1 9 8 0 - 1 9 9 0}$ & 0.0 & 0.5 & -0.4 \\
$\mathbf{1 9 9 0 - 2 0 0 0}$ & 0.2 & 0.2 & 0.0 \\
$\mathbf{2 0 0 0 - 2 0 1 0}$ & 0.4 & -0.2 & 0.6 \\
$\mathbf{1 9 8 0 - 2 0 1 0}$ & 0.7 & 2.3 & -1.5 \\
\hline
\end{tabular}

Panel B. Change in the spatial mismatch for the low-skilled population.

\begin{tabular}{|c|c|c|c|}
\hline & \multirow{2}{*}{$\begin{array}{c}\text { Total change in the spatial } \\
\text { mismatch (pp) }\end{array}$} & \multicolumn{2}{|c|}{ Change due to } \\
\hline & & Employment shifts (pp) & Population shifts (pp) \\
\hline 1980-1990 & -1.3 & 0.9 & -2.2 \\
\hline $1990-2000$ & 0.7 & 0.9 & -0.2 \\
\hline 2000-2010 & 1.7 & -0.4 & 2.1 \\
\hline 1980-2010 & 1.1 & 3.0 & -1.8 \\
\hline
\end{tabular}

Panel C. Change in the spatial mismatch for the high-skilled population.

Total change in the spatial mismatch (pp)

\section{Change due to}

Employment shifts (pp) Population shifts (pp)

\begin{tabular}{lccc}
\hline $\mathbf{1 9 8 0 - 1 9 9 0}$ & -0.2 & -0.4 & 0.2 \\
$\mathbf{1 9 9 0 - 2 0 0 0}$ & -0.1 & 0.2 & -0.3 \\
$\mathbf{2 0 0 0 - 2 0 1 0}$ & -0.2 & -0.1 & -0.1 \\
$\mathbf{1 9 8 0 - 2 0 1 0}$ & -0.5 & 0.2 & -0.7 \\
\hline \hline
\end{tabular}

Source: County Business Patterns, decennial censuses and Community Survey. 
Table 4. Decomposition of the DSMI into SMI and distance, 1980-2010.

\begin{tabular}{|c|c|c|c|c|c|c|c|c|c|}
\hline & \multicolumn{3}{|c|}{ Total } & \multicolumn{3}{|c|}{ Low-skilled } & \multicolumn{3}{|c|}{ High-skilled } \\
\hline & $\begin{array}{c}\text { DSMI } \\
(\%)\end{array}$ & $\begin{array}{c}\text { SMI } \\
(\%)\end{array}$ & $\begin{array}{c}\text { D } \\
\text { (miles) }\end{array}$ & $\begin{array}{c}\text { DSMI } \\
(\%)\end{array}$ & $\begin{array}{l}\text { SMI } \\
(\%)\end{array}$ & $\begin{array}{c}\text { D } \\
\text { (miles) }\end{array}$ & $\begin{array}{c}\text { DSMI } \\
(\%)\end{array}$ & $\begin{array}{l}\text { SMI } \\
(\%)\end{array}$ & $\underset{\text { (miles) }}{\text { D }}$ \\
\hline 1980 & 0.8 & 6.5 & 358.3 & 3.4 & 11.7 & 803.8 & 1.7 & 8.0 & 588.5 \\
\hline 1990 & 0.9 & 6.2 & 394.8 & 2.1 & 11.2 & 516.7 & 1.5 & 7.2 & 578.6 \\
\hline 2000 & 1.1 & 6.4 & 456.7 & 2.8 & 14.0 & 557.5 & 1.4 & 6.9 & 567.9 \\
\hline 2010 & 1.5 & 5.7 & 726.2 & 4.5 & 14.8 & 851.5 & 1.2 & 6.2 & 535.4 \\
\hline $\begin{array}{r}\text { Change 1980- } \\
2010\end{array}$ & $0.7 \mathrm{pp}$ & $-0.8 \mathrm{pp}$ & 367.9 & $1.1 \mathrm{pp}$ & $3.1 \mathrm{pp}$ & 47.7 & $-0.5 \mathrm{pp}$ & $-1.8 \mathrm{pp}$ & -53.1 \\
\hline $\begin{array}{r}\text { Ratio } \\
2010 / 1980 \\
\end{array}$ & 1.8 & 0.9 & 2.0 & 1.3 & 1.3 & 1.1 & 0.7 & 0.8 & 0.9 \\
\hline
\end{tabular}

Source: County Business Patterns, decennial censuses and Community Survey.

Table 5. Spatial mismatch indices using alternative distance measures.

\begin{tabular}{|c|c|c|c|c|c|c|c|c|c|}
\hline & \multicolumn{3}{|c|}{1980} & \multicolumn{3}{|c|}{2010} & \multicolumn{3}{|c|}{ Change 1980-2010 } \\
\hline & $\begin{array}{c}\text { Total } \\
(\%)\end{array}$ & $\begin{array}{c}\text { Low- } \\
\text { skilled } \\
(\%)\end{array}$ & $\begin{array}{c}\text { High- } \\
\text { skilled } \\
(\%)\end{array}$ & $\begin{array}{c}\text { Total } \\
(\%)\end{array}$ & $\begin{array}{c}\text { Low- } \\
\text { skilled } \\
(\%)\end{array}$ & $\begin{array}{c}\text { High- } \\
\text { skilled } \\
(\%)\end{array}$ & $\begin{array}{l}\text { Total } \\
\text { (pp) }\end{array}$ & $\begin{array}{l}\text { Low- } \\
\text { skilled } \\
\text { (pp) }\end{array}$ & $\begin{array}{l}\text { High- } \\
\text { skilled } \\
\text { (pp) }\end{array}$ \\
\hline Linear distance & 0.8 & 3.4 & 1.7 & 1.5 & 4.5 & 1.2 & 0.7 & 1.1 & -0.5 \\
\hline No distance (SMI) & 6.5 & 11.7 & 8.0 & 5.7 & 14.8 & 6.2 & -0.7 & 3.1 & -1.8 \\
\hline Alt. 1 & 4.4 & 8.8 & 5.6 & 4.3 & 11.6 & 4.4 & -0.1 & 2.8 & -1.2 \\
\hline Alt. 2 & 4.1 & 8.6 & 5.4 & 4.4 & 12.0 & 4.3 & 0.2 & 3.5 & -1.1 \\
\hline Alt. 3 & 1.9 & 4.9 & 3.4 & 3.0 & 8.3 & 2.5 & 1.1 & 3.4 & -0.9 \\
\hline
\end{tabular}

Source: County Business Patterns, decennial censuses and Community Survey. SMI = spatial mismatch index. Alt. 1 = natural log of linear distance. Alt. 2 = concentric circles using Census cut-off distances. Alt. 3 = concentric circles using in-sample distance percentiles. 